\title{
Mashed potatoes enriched with soy protein isolate and inulin: chemical, rheological and structural basis
}

\author{
MD Alvarez, MD Olivares, M Blanch and W Canet
}

\begin{abstract}
Soy protein isolate is typical vegetable protein with health-enhancing activities. Inulin, a prebiotic no digestible carbohydrate, has functional properties. A mashed potato serving of $200 \mathrm{~g}$ with added soy protein isolate and/ or inulin concentrations of $15-60 \mathrm{~g} \mathrm{~kg}^{-1}$ provides from 3 to $12 \mathrm{~g}$ of soy protein isolate and/or inulin, respectively. Currently, no information is available about the possible texture-modifying effect of this non-ionizable polar carbohydrate in different soy-based food systems. In this study, the effect of the addition of soy protein isolate and inulin blends at different soy protein isolate: inulin ratios on the degree of inulin polymerization and the rheological and structural properties of fresh mashed and frozen/thawed mashed potatoes were evaluated. The inulin chemical structure remained intact throughout the various treatments, and soy protein isolate did not affect inulin composition being a protein compatible with this fructan. Small-strain rheology showed that both ingredients behaved like soft fillers. In the frozen/thawed mashed potatoes samples, addition of $30: 30$ and 15:60 blend ratios significantly increased elasticity ( $G^{\prime}$ value) compared with 0:0 control, consequently reducing the freeze/thaw stability conferred by the cryoprotectants. Inulin crystallites caused a significant strengthening effect on soy protein isolate gel. Micrographs revealed that soy protein isolate supports the inulin structure by building up a second fine-stranded network. Thereby, possibility of using soy protein isolate and inulin in combination with mashed potatoes to provide a highly nutritious and healthy product is promising.
\end{abstract}

\section{Keywords}

Soy protein isolate, long-chain inulin, high-performance liquid chromatography with pulsed amperometric detection, viscoelasticity, microstructure

\section{INTRODUCTION}

Soy protein isolate (SPI), the most refined form of soy protein with a minimum $90 \%$ protein content, is a versatile food ingredient that can improve food products' organoleptic characteristics and nutritional values (Tseng et al., 2009). The US Food and Drug Administration (FDA) determined that diets containing $25 \mathrm{~g}$ of soy protein can reduce levels of low-density lipoproteins (bad cholesterol) by as much as $10 \%$ (Federal Register, 1998). SPIs are composed of a mixture of albumins and globulins, 90\% of which are globular storage proteins made up of mainly $7 \mathrm{~S}$ ( $\beta$-conglycinin) and $11 \mathrm{~S}$ (glycinin) globulins. SPIs have also been reported as having specific functional properties, determined by structural changes that enable them to modify the physical properties of food products (Hagenimana et al., 2007). 
The non-digestible fructans inulin (INL) and oligofructose are of interest in human nutrition due to their prebiotic effect, i.e., specific stimulation of colonic bacterial growth and/or activity that benefits the host, as well as inhibiting the growth of pathogens and harmful microorganisms (Roberfroid, 2007). Native INL is mainly obtained industrially from chicory roots and is a mixture of oligomer and polymer chains with a variable number of fructose molecules, joined by $\beta$ bonds $(2$ $\rightarrow 1$ ), which usually include a glucose molecule at the end of the chain (González-Tomás et al., 2008). However, whereas native INL contains molecules with different degrees of polymerization (DP) (from 2 to 60 ), the commercial products obtained industrially only contain short-chain INL (oligofructose) (2-7 units) or long-chain INL (22-25 units). For INL-type prebiotics, the DP determines their unique functionalites (Tseng et al., 2009). Short-chain INL is much more soluble and sweeter than native INL, with a sweetness profile similar to that of sucrose, while long-chain INL is more thermally stable, less soluble and more viscous than the native variety (Wada et al., 2005) and can be used to structure low-fat foods. González-Tomás et al. (2008) observed that long-chain INL used as a fat replacer in skimmed-milk starch-based dairy desserts must be added at over $7 \mathrm{~g} / 100 \mathrm{~g}$ of product to obtain similar rheological properties as whole-milk samples with the same starch concentration. A fat-like texture can be obtained by increasing the concentration and average INL DP above a critical value (Kim et al., 2001). In most cases, INL addition to different foods has been done either to increase fiber ingestion, in amounts that range from 3 to $6 \mathrm{~g}$ per portion, or to assure its bifidogenic nature, by adding 3-8g per portion (Coussement, 1999).

However, little information is available on how INL chemical characteristics may be affected by interactions with other ingredients or by the freezing and thawing processes. The INL chemical structure can be determined employing chromatographic techniques, such as anion-exchange high-performance liquid chromatography (HPLC) with pulsed amperometric detection (HPAEC-PAD). This is a sensitive and widely used chromatographic system for separation and analysis of underivatized carbohydrates that can form anions in high-pH eluents because of their weak acidity (Chiavaro et al., 2007). By applying this technique, Leroy et al. (2010) studied the changes in INL and soluble sugar concentration in artichokes during storage.

A previous study showed that the addition of INL alone $\left(0,15,30,45\right.$ and $\left.60 \mathrm{~g} \mathrm{~kg}^{-1}\right)$ to both fresh mashed (FM) and frozen/thawed mashed potatoes (F/TM) samples had a limited effect on the thickening of the product as INL did not seem to act synergistically with potato starch (Alvarez et al., 2011). However, no information is available about the possible texturemodifying effect resulting of the addition of SPI/INL blends to mashed potatoes or by freezing and thawing these products. The addition of new ingredients will produce perceptible differences in the physical and sensory properties of the final product, and rheological measurements are widely used to characterize the structure of food products. INL was found to enhance the viscoelastic properties of glucono- $\delta$-lactone-induced cold-set soy protein gels (Tseng et al., 2009). Specifically, small-amplitude oscillatory shear analyses of samples containing protein are useful for determining the nature of the protein matrix without damaging it (Tunick, 2011). When used in conjunction with other analytical techniques, a clear picture of biopolymer behavior at the molecular level can be obtained.

As a consequence of the limited information available about the possibly texture-modifying effect of INL-type prebiotics in different soy-based food systems, it was considered of interest to investigate the effect of using SPI and INL in combination with mashed potatoes, not only to provide a useful alternative to other highly nutritious and healthy food products but also simultaneously derive a mechanistic understanding of the structures involved in the systems. The objective of this study was to evaluate: (a) the effect of the SPI:INL blend ratio and (b) the effect of the freeze/thaw cycle on the degree of INL polymerization, the dynamic rheological properties and the structural characteristics (microstructure) of mashed potatoes. An accurate preservation of the structural and molecular integrity of these functional ingredients is desirable to promise the adequate nutritional performance.

\section{MATERIALS AND METHODS}

\section{Materials}

The potatoes used were tubers (cv. Kennebec) from Aguilar de Campoo (Burgos, Spain). Readily dispersible SPI with the trade name PRO-FAM ${ }^{\circledR} 646$ (ADM, Netherlands) was used in this study without more purification. According to the product specification sheets, the proximate composition $\left(\mathrm{g} \mathrm{kg}^{-1}\right)$ was as follows: protein $(N \times 6.25)>900$, moisture $<60$, fat $<40$ and ash $<50$. INL with the trade name Orafti ${ }^{\circledR} \mathrm{HP}$ (BENEO-Orafti, Tienen, Belgium) was a "long-chain" INL with a average $\mathrm{DP} \geq 23$ and purity of $99.5 \%$ (producer's data). Kappa-carrageenan $(\kappa-\mathrm{C})$ (GENULACTA carrageenan type LP-60) and xanthan gum (XG) (Keltrol F [E]) were donated by Premium Ingredients, S.L. (Girona, Spain). According to ranging-finding experiments and previous studies (Alvarez et al., 2011), the following SPI: INL ratio blends were added to samples: 15:45 (that is 
$15 \mathrm{~g} \mathrm{~kg}^{-1}$ of the total raw ingredients (SPI) $/ 45 \mathrm{~g} \mathrm{~kg}^{-1}$ (INL)), 30:30, 45:15, 15:60, 30:45, 45:30, 60:15 and $60: 60$. Two controls were also prepared (FM and $\mathrm{F} / \mathrm{TM}$ potatoes) without any other ingredient addition ( $0: 0$ controls), as well as samples with only $60 \mathrm{~g} \mathrm{~kg}^{-1}$ of added INL $(0: 60)$ and with $60 \mathrm{~g} \mathrm{~kg}^{-1}$ of added SPI alone $(60: 0)$.

\section{Preparation of mashed potatoes}

Tubers were manually washed, peeled and diced. Mashed potatoes were prepared in $\sim 1350$-g batches from $605.9 \mathrm{~g} \mathrm{~kg}^{-1}$ of potatoes, $230 \mathrm{~g} \mathrm{~kg}^{-1}$ of semiskimmed in-bottle sterilized milk, $153.4 \mathrm{~g} \mathrm{~kg}^{-1}$ of water, $7.7 \mathrm{~g} \mathrm{~kg}^{-1}$ of salt $(\mathrm{NaCl})$ and $1.5 \mathrm{~g} \mathrm{~kg}^{-1}$ of either $\kappa$-C or $\mathrm{XG},{ }^{13}$ using a TM 31 food processor (Vorwerk España, M.S.L., S.C., Madrid, Spain). INL $\left(0-60 \mathrm{~g} \mathrm{~kg}^{-1}\right)$ was previously dissolved in the $230 \mathrm{~g} \mathrm{~kg}^{-1}$ of milk and $100 \mathrm{~g} \mathrm{~kg}^{-1}$ of water at $70^{\circ} \mathrm{C}$ for $15 \mathrm{~min}$ and stirred constantly with a magnetic stirrer. The ingredients were first cooked for $30 \mathrm{~min}$ at $90^{\circ} \mathrm{C}$ (blade speed: $0.10 \times g)$ and any evaporated water was replaced gravimetrically. In terms of processability, there were serious difficulties in cooking SPI together with the rest of the ingredients, especially when SPI levels were over $45 \mathrm{~g} \mathrm{~kg}^{-1}$. The SPI concentration of $15-60 \mathrm{~g} \mathrm{~kg}^{-1}$ which had previously been hydrated at a ratio of SPI to water of $1: 5$ was then added at this point. Water used to hydrate SPI was removed from initial water content $\left(153.4 \mathrm{~g} \mathrm{~kg}^{-1}\right)$. Next, all the ingredients were cooked for an additional $5 \mathrm{~min}$ at $90^{\circ} \mathrm{C}$. The mash was ground for $40 \mathrm{~s}$ (blade speed: $80 \times g$ ) and $20 \mathrm{~s}$ (blade speed: $450 \times g$ ), and then homogenized immediately through a stainless steel sieve (diameter: $1.5 \mathrm{~mm}$ ). Two batches were continuously being prepared and blended and half of each fresh mashed (FM) was analyzed immediately whilst the other half was subjected to a freeze/thaw cycle (F/TM). Two repetitions of each composition were prepared. Performance of a freeze/ thaw cycle and heating procedure has been previously described (Alvarez et al., 2009, 2011). The sample testing temperature was set at $55^{\circ} \mathrm{C}$ as this is the preferred temperature for mashed potatoes consumption.

\section{Extraction and chromatographic determination of INL}

Samples of $3 \mathrm{~g}$ of FM and F/TM potatoes were extracted and homogenized in $10 \mathrm{~mL}$ of ultra-pure water. The centrifugation was conducted at $6000 \times \mathrm{g}$ for $30 \mathrm{~min}$ at $4{ }^{\circ} \mathrm{C}$ and the supernatant was filtered through a $0.45 \mu \mathrm{m}$ pore membrane filter and degassed before injection into the HPLC system. The process was run in triplicate. Two aliquots of $1.4 \mathrm{~mL}$ were analyzed on an HPLC-carbohydrate column Metrosep Carb
1-250 with anion chromatography 817 Bioscan (Metrohm, Herisau, Switzerland) using PAD. The gradient was established by mixing eluent A (100 mm $\mathrm{NaOH}$ in $10 \mathrm{mM}$ acetate-Na) with eluent B $(400 \mathrm{mM}$ sodium acetate in $100 \mathrm{mM} \mathrm{NaOH}$ ) in the following ways: $0-20 \mathrm{~min} \quad 80-55 \% \mathrm{~A} ; 20-30 \mathrm{~min} 55-35 \% \mathrm{~A}$; $30-56 \mathrm{~min} 35-10 \% \mathrm{~A} ; 56-60 \mathrm{~min} 10-80 \% \mathrm{~A}$; flow rate through the column was $1.0 \mathrm{~mL} \mathrm{m^{-1 }}$ leading to a 60 min sampling time $\left(t_{\mathrm{s}}\right)$. The applied PAD potentials for E1 $(400 \mathrm{~ms}), E 2(200 \mathrm{~ms})$ and E3 $(400 \mathrm{~ms})$ were $+0.05,+0.75$ and $-0.15 \mathrm{~V}$, respectively.

\section{Oscillatory shear measurements}

A Bohlin CVR 50 controlled stress rheometer (Bohlin Instruments Ltd., Cirencester, UK) was used to conduct non-destructive oscillatory shear testing using a plateplate sensor system with a $2 \mathrm{~mm}$ gap (PP40, 40 mm) and a solvent trap to minimize moisture loss during tests. After loading the sample, there was a 5-min waiting period to allow the sample to recover and reach $55^{\circ} \mathrm{C}$. Temperature control at $55^{\circ} \mathrm{C}$ was achieved with a Peltier Plate system $\left(-40\right.$ to $+180^{\circ} \mathrm{C}$; Bohlin Instruments). In order to determine the linear viscoelastic (LVE) region, stress sweeps were run first at a constant frequency $(\omega)$ of $1 \mathrm{rad} \mathrm{s}^{-1}$ over a shear stress range of $3-300 \mathrm{~Pa}$, which covered the linear and non-linear ranges of the systems. Storage modulus $\left(G^{\prime}, \mathrm{Pa}\right)$, loss modulus $\left(G^{\prime \prime}, \mathrm{Pa}\right)$ and the ratio of $G^{\prime \prime}$ to $G^{\prime}$, represented by the resulting loss tangent $(\tan \delta$ ) values were registered within the LVE region. Next three frequency sweeps were performed over the $\omega$ range of $0.1-100 \mathrm{rad}$ $\mathrm{s}^{-1}$, and again the $G^{\prime}, G^{\prime \prime}$ and $\tan \delta$ values were registered at $1 \mathrm{rad} \mathrm{s}^{-1}$. As a new sample was used each time for the dynamic tests, the resulting values were average values of the four determinations. In addition, a power-law type relationship was verified by the dynamic rheological data from the frequency sweeps; linear regressions of $\ln \left(G^{\prime}\right)$ and $\ln \left(G^{\prime \prime}\right)$ vs. $\ln (\omega)$ were carried out and the slope magnitudes ( $n$ ' and $\left.n^{\prime \prime}\right)$ were computed as described in previous works (Alvarez et al., 2011).

\section{Other physical and chemical characteristics}

Water activity $\left(\mathrm{a}_{\mathrm{w}}\right)$ was measured with a LabMaster- $\mathrm{a}_{\mathrm{w}}$ (Novasina AG CH-8853, Lachen, Switzerland). Protein content was calculated using the Dumas combustion method (Moore et al., 2010), and total nitrogen in FM and F/TM potatoes was determined with a Leco FP-2000 protein/nitrogen analyzer (Leco Corp., St. Joseph, MI, USA). The results were expressed as $g$ total protein per $\mathrm{kg}$ of sample. All these measurements were performed in quadruplicate and the results averaged. 


\section{Scanning electron microscopy}

Mashed potatoes microstructure was examined by using a Hitachi S-2100 scanning electron microscope (Hitachi, Ltd., Tokyo, Japan) (National Center for Metallurgical Research (CENIM)-CSIC). Samples were air-dried, then mounted and sputter-coated with $\mathrm{Au}$ (200 A approx.) in an SPI diode sputtering system metallizer. Micrographs were taken with a digital system Scanvision 1.2 of Röntgenanalysen-Technik (RONTEC) (GmbH, Berlin, Germany) $(800 \times 1.200$ pixel).

\section{Statistical analysis}

A two-way ANOVA with interaction was applied to evaluate how SPI: INL ratio and performance or not of a freeze/thaw cycle affected the rheological data, $a_{w}$ and the total protein of the mashed potatoes. Minimum significant differences were calculated using Fisher's least significant difference (LSD) tests with $99 \%$ confidence interval. Analyses were performed by using Statgraphics ${ }^{\circledR}$ software version 5.0 (STSC Inc., Rockville, MD, USA).

\section{RESULTS AND DISCUSSION Characterization of INL in FM and F/TM potatoes}

The average DP and distribution of saccharides in INL (Orafti ${ }^{\circledR} \mathrm{HP}$ ) added to FM and F/TM potatoes were qualitatively evaluated by HPAEC-PAD. Figure 1(A) and $(B)$ shows chromatograms of superposed FM and $\mathrm{F} / \mathrm{TM}$ potatoes with added blend ratios of $60: 60$ and $45: 30$, respectively. The FM elution profiles and their F/ TM counterparts were very similar in both SPI : INL ratios. Similar results were obtained for all the other added SPI : INL ratios (data not shown). These results indicate that the freeze/thaw cycle did not influence the DP of the INL. Consequently, temperatures as

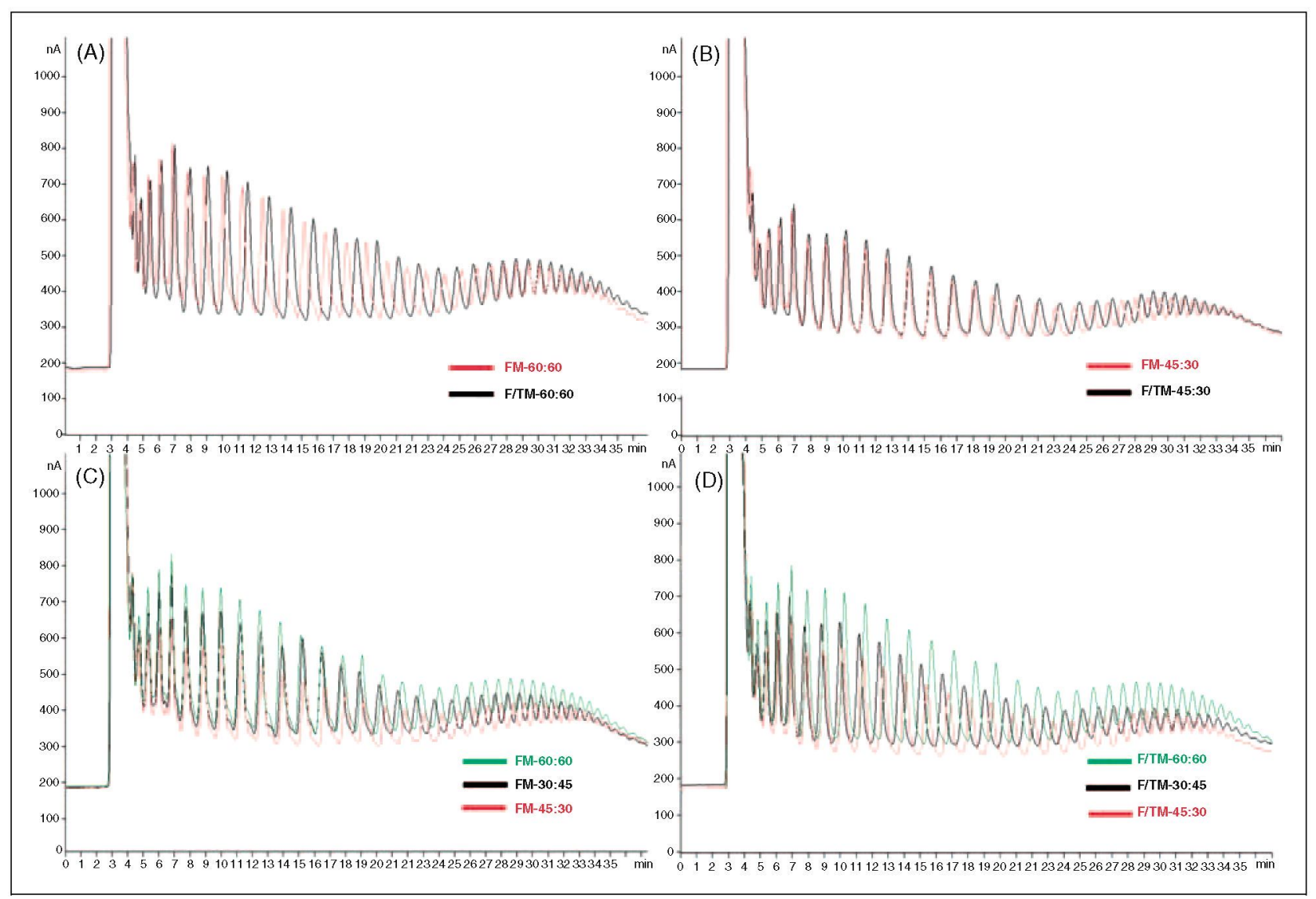

Figure 1. HPAEC-PAD chromatograms obtained for fresh mashed (FM) and frozen/thawed mashed potatoes (F/TM) with different added SPI:INL ratios. (A) FM and F/TM potatoes with 60:60 added ratio, (B) FM and F/TM potatoes with added 45:30 ratio, (C) FM potatoes with 30:45, 45:30 and 60:60 added ratios and (D) F/TM potatoes with added 30:45, 45:30 and 60:60 ratios. HPAEC-PAD: high-performance liquid chromatography with pulsed amperometric detection; INL: inulin; SPI: soy protein isolate. 
low as $-24^{\circ} \mathrm{C}$ did not induce an increase in reducing sugar concentrations nor a decrease in average INL chain length. The glycosidic bond of INL can withstand thermal stress between freezing and up to $80^{\circ} \mathrm{C}$. HPAEC-PAD was also used to compare the INL profile of fresh and stored $\left(18^{\circ} \mathrm{C}, 4^{\circ} \mathrm{C}\right.$ and $4^{\circ} \mathrm{C}$ under polypropylene film packing) artichokes (Leroy et al., 2010). In this case, INL content in artichoke was strongly influenced by storage temperature and preservation method. During the storage of artichoke, INL depolymerization involved a decrease in INL content and in average DP, associated with an increase of reducing sugars modulated by two enzymes. Positively, the low temperature reached by the F/TM potatoes slowed the biochemical reactions which, together with the reduction in $\mathrm{a}_{\mathrm{w}}$ due to freezing, can maintain the initial quality almost without changes (Canet, 1989). Thereby, F/TM samples retain the INL prebiotic effect.

On the other hand, heat processing is a prerequisite for the production of mashed potatoes as indicated above. The chromatographic profiles show that all the peaks were eluted between 3 and $35 \mathrm{~min}$, revealing that INL was mainly composed of polymeric fructans having DP higher than 23 (Chiavaro et al., 2007). As producer specifications gave this INL a $\mathrm{DP} \geq 23$, it means that the mashed potatoes manufacturing process did not degrade the INL structure, thus confirming the findings of Glibowski and Wasko (2008), who investigated the changes in INL structure after heating highly polymerized INL solutions with different $\mathrm{pH}$ values. Reducing sugars, cryoscopy and HPLC analyses revealed that the INL chemical structure is stable in neutral and slightly acidic conditions $(\mathrm{pH}$ 5), while gelation of the highly polymerized INL solution after heating at $\mathrm{pH} 7$ and $80^{\circ} \mathrm{C}$ could be inhibited after dissolution of INL crystallites which act as seeding crystals. In this study, the average final $\mathrm{pH}$ of FM potatoes was 5.9 and this was not modified by the SPI: INL ratio. Bot et al. (2004) reported that when the temperature exceeded $70^{\circ} \mathrm{C}$, the INL crystallites with an average DP of 10 dissolved, making the formation of gel impossible. In turn, after reducing sugar content analysis, Kim et al. (2001) surmised that temperatures above $80^{\circ} \mathrm{C}$ in neutral conditions caused some degree of hydrolysis of dissolved highly polymerized INL molecules. In these systems, the presence of other polysaccharides such as potato starch, $\kappa$-C and $X G$ probably influenced and increased the INL chain hydrolysis temperature thus explaining why long INL chains were not degraded into smaller ones after heating at $90^{\circ} \mathrm{C}$ for $35 \mathrm{~min}$. By comparing Figure 1(A) and (B), it is also possible to observe that in chromatograms of samples with lower INL concentrations, the quantified peak heights are lower. The effect of INL concentrations on peak heights is better visualized in
Figure 1(C) and (D). In both FM samples and their F/ TM counterparts, it can be seen that by decreasing the INL content, there is a corresponding lineal decrease in the size of the detected peaks. Therefore, the method used is perfectly useful for detecting and distinguishing between the different INL levels added to the mashed potatoes.

In turn, the chromatograms shown in Figure 2(A) and (B) include the superposition of FM and F/TM potatoes without added ingredients $(0: 0$ ratio), together with close-up views of each sample. In both $0: 0$ controls, several smaller peaks can be observed, which were initially attributed to the presence of potato starch, $\mathrm{XG}$ or $\kappa-\mathrm{C}$ in the systems. Both $\mathrm{XG}$ and $\kappa-\mathrm{C}$ are added to the mashed potatoes to ameliorate the detrimental effects (syneresis, amylose retrogradation and rheological changes) of the freeze/thaw cycle (Alvarez et al., 2009). The corresponding profiles of XG and $\kappa$-C samples which were dissolved in water at a concentration of $20 \mathrm{ppm}$ and then injected singly are also included in Figure 2(A) and (B), respectively. $\mathrm{XG}$ dissolved in water was not well detected, since most of the gum was resolved at the start of the chromatogram. Analogously, $\kappa$-C dissolved in water was resolved in a single well-defined peak with a retention time of $3 \mathrm{~min}$. As can be observed, the detected peaks did not correspond to either XG or $\kappa-\mathrm{C}$, therefore we assume that the small peaks detected in the controls may be attributed to potato starch remnants present in the systems. The fact that the peaks detected in the controls are smaller in F/TM samples would seem to indicate that the freeze/thaw cycle affects the basic potato starch structure. The addition of small amounts of XG to white sauces made with starches from different botanical sources significantly improved freeze/thaw stability (Arocas et al., 2009). According to the latter authors, this was probably due to XG interaction with solubilized amylose, reducing amylose-amylose interactions and therefore the extent of retrogradation. Therefore, the freeze/thaw stability conferred by XG was predictable, given the decrease in peak heights detected in the F/TM control as compared to its FM counterpart. Moreover, by comparing the different profiles shown, it can be seen that in mashed potatoes enriched with INL, whether alone or blended with SPI, the potato starch peaks were masked by the presence of INL.

Shown in Figure 2(C) and (D) are the chromatograms of superposed FM with added $0: 60$ and $60: 60$ blend ratios and their respective $\mathrm{F} / \mathrm{TM}$ counterparts. No differences were detected between FM and F/TM samples, indicating that in this case too, the INL chemical structure was not affected by SPI enrichment. Conversely, heat treatment does induce dissociation, denaturation and aggregation of soy protein (Sorgentini et al., 1995), and freezing also brought 
about some changes in the processing characteristics of soybeans. When soy protein solution was frozen, the proteins became partially insoluble due to the polymerization of protein molecules through the formation of intermolecular disulphide bonds (Hashizume et al., 1971). However, such SPI structural changes did not affect INL composition, being a protein entirely compatible with this fructan.

\section{Dynamic rheological properties}

The ANOVA showed that both the SPI: INL ratio and the freeze/thaw cycle significantly affected all the dynamic properties and rheological characteristics derived $(p<0.01)$ (Table 1$). F$ values are shown in order to point out the significance of the main effects. All samples exhibited the viscoelastic properties usually observed for weak-gel systems, which is typical in this type of product (Alvarez et al., 2011), with a dominant elastic feature. This can be clearly seen from the $\tan \delta$ $\left(G^{\prime \prime} / G^{\prime}\right)$ values because $\tan \delta$ is less than 0.3 but greater than 0.1 in all cases. Magnitudes of the resulting straight lines ( $n^{\prime}$ and $n^{\prime \prime}$ slopes) were small and, except for the 15:60 ratio, $n^{\prime}$ values were higher than $n^{\prime \prime}$ values, manifesting that $G^{\prime}$ was more frequencydependent than $G^{\prime \prime}$. $G^{\prime}$ became more frequencyindependent in samples with added 0:60 and 15:60 ratios than in the $0: 0$ controls, indicative of a more solid-like behavior at these SPI:INL blends. González-Tomás et al. (2008) reported that by adding $7.5 \%$ of long-chain INL to low-fat starch-based custard desserts, they obtained viscoelastic properties similar to the whole-milk sample. Conversely, SPI alone, at $60 \mathrm{~g} \mathrm{~kg}^{-1}$, weakened the amylose/amylopectin matrix (higher $n^{\prime}$ values) as compared to the addition of the same concentration of INL alone. The presence of INL at the same concentration (60:60 ratio) had no remarkable effect on the $n^{\prime}$ value when compared with the samples with added SPI alone. Tunick (2011) reported that the $n^{\prime}$ value for egg albumen was 0.114 , indicating a strong cross-linked gel, whereas the $n^{\prime}$ value for whey protein isolate was relatively high at 0.454 , indicating a weak physical gel. Moreover, both slopes were lower after freezing and thawing processes, demonstrating

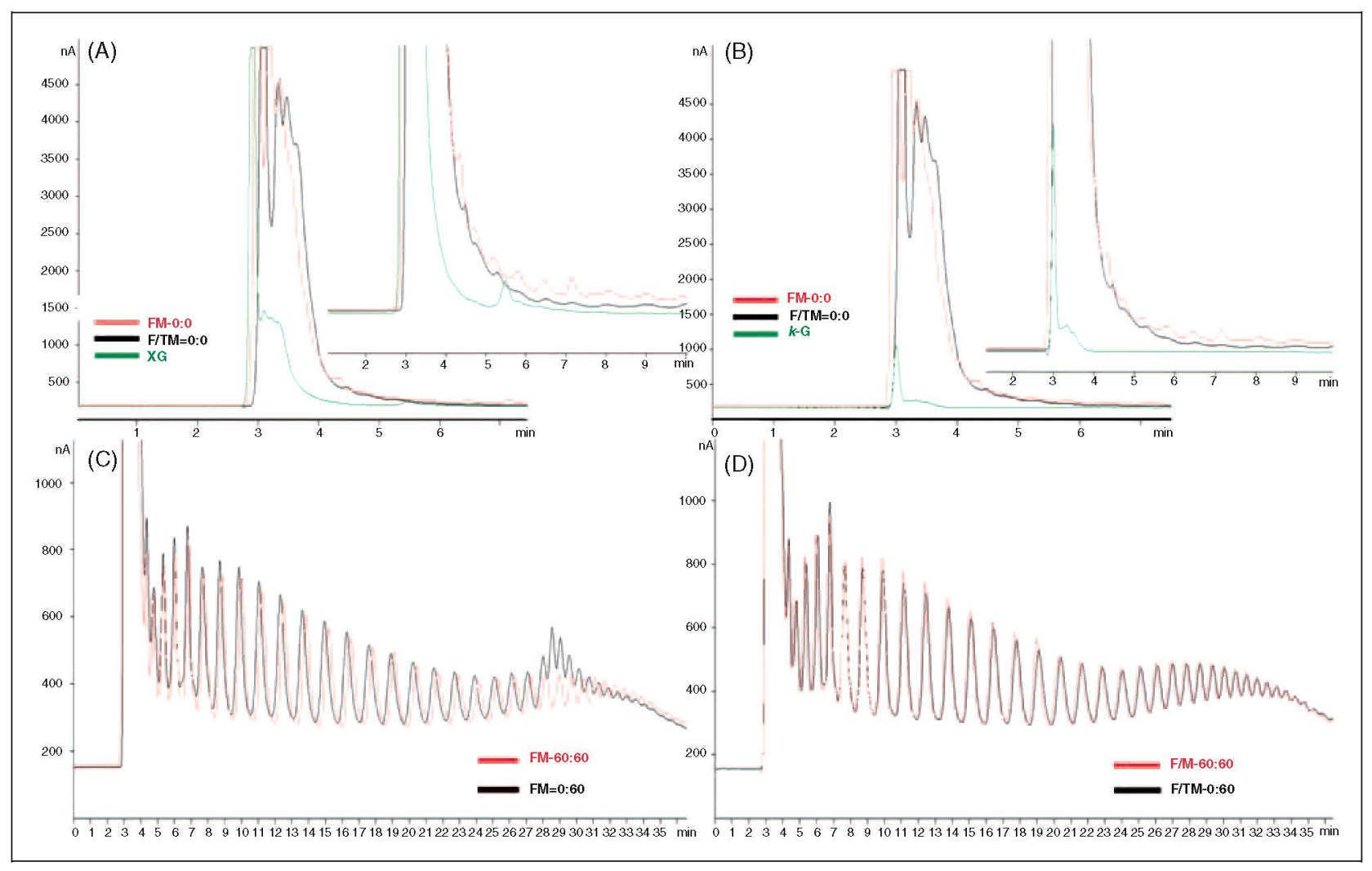

Figure 2. HPAEC-PAD chromatograms obtained for fresh mashed (FM) and frozen/thawed mashed potatoes (F/TM) with different added SPI:INL ratios. (A) FM and F/TM potatoes with 0:0 ratio together xanthan gum dispersion, (B) FM and F/TM potatoes with 0:0 ratio together kappa-carrageenan dispersion, (C) FM potatoes with added 0:60 and 60:60 ratios and (D) F/TM potatoes with added 0:60 and 60:60 ratios. HPAEC-PAD: high-performance liquid chromatography with pulsed amperometric detection; INL: inulin; SPI: soy protein isolate. 
that the frequency dependence of both moduli was lower after the freeze/thaw cycle.

Shown in Table 1 are also the average ratios of $G^{\prime}$ to $G^{\prime \prime}$ and of complex modulus $\left(G^{*}\right)$ to $G^{\prime}$ in the $\omega$ range studied. The $G^{\prime} / G^{\prime \prime}$ ratio was close to 4 for the FM potatoes and nearly 5 for the F/TM ones, supporting that the frozen/thawed product behaves like a stronger gel structure. On the other hand, samples with the added 15:60 ratio exhibited the highest $G^{\prime} / G^{\prime \prime}$ ratio values, whereas those with the $60: 60$ added ratio showed the lowest. Therefore, with a fixed INL content, these results imply that by increasing SPI concentrations up to $60 \mathrm{~g} \mathrm{~kg}^{-1}$, there would be a decreased number of intermolecular cross-links resulting in a weaker matrix. This behavior is typical of gels filled with deformable particles (Jampen et al., 2001). In gels containing deformable particles, the linear decrease in $G^{\prime}$ in line with increasing volume fractions may be due to particle compliance under stress or to particle separation from the matrix, thereby causing the gel to weaken. SPI played a more significant role in the decrease of viscoelastic properties of the systems than INL.

In turn, the ratio $G^{*} / G^{\prime}$ was close to 1.04 for the FM potatoes and nearly 1.02 for the F/TM ones (Table 1 ). The lower $G^{*} / G^{\prime}$ values corresponded to samples with added $0: 60$ and $15: 60$ ratios. Therefore, both freezing/ thawing processes and the addition of high INL concentrations and low SPI content also decreased the relative contribution of the viscous component to the viscoelasticity of mashed potatoes. As a consequence, $\tan \delta$ is also lower in mashed potatoes with added $0: 60$ and 15:60 ratios. In this study, at the highest INL concentration used $\left(60 \mathrm{~g} \mathrm{~kg}^{-1}\right)$, INL particles formed

Table 1. Effects of SPI:I ratio and a freeze/thaw cycle on dynamic rheological properties and characteristics, water activity and total protein of mashed potatoes with added SPI/INL blends. Means, $F$ and $p$ values

\begin{tabular}{|c|c|c|c|c|c|c|c|c|c|}
\hline Source & $\mathrm{G}^{\prime}(\mathrm{Pa})$ & $\mathrm{G}^{\prime \prime}(\mathrm{Pa})$ & $\tan \delta$ & $n^{\prime}$ & $n^{\prime \prime}$ & $G^{\prime} / G^{\prime \prime}$ & $G^{*} / G^{\prime}$ & $a_{w}$ & $\begin{array}{l}\text { Total } \\
\text { protein } \\
\left(\mathrm{g} \mathrm{kg}^{-1}\right)\end{array}$ \\
\hline \multicolumn{10}{|l|}{ Main effects: } \\
\hline \multicolumn{10}{|l|}{ A: SPI:INL ratio } \\
\hline $0: 09419.71 \mathrm{a}$ & $2244.25 \mathrm{a}$ & $0.240 \mathrm{a}-\mathrm{c}$ & $0.141 b$ & $0.055 e$ & $4.32 b-d$ & $1.031 b$ & $0.980 \mathrm{c}, \mathrm{d}$ & $24.70 \mathrm{e}$ & \\
\hline $0: 60$ & $7975.25 c$ & $1743.75 b, c$ & $0.208 \mathrm{~d}, \mathrm{e}$ & $0.126 \mathrm{c}$ & $0.067 \mathrm{~d}, \mathrm{e}$ & $4.61 \mathrm{~b}$ & $1.025 \mathrm{c}, \mathrm{d}$ & $0.985 a, b$ & $24.75 \mathrm{e}$ \\
\hline $15: 45$ & $5693.87 d$ & $1416.37 d$ & $0.245 a-c$ & $0.149 a, b$ & $0.090 \mathrm{c}$ & $4.07 \mathrm{c}, \mathrm{d}$ & $1.033 a, b$ & $0.984 \mathrm{a}, \mathrm{b}$ & $35.05 d$ \\
\hline $30: 30$ & $8169.00 \mathrm{~b}, \mathrm{c}$ & $1965.50 \mathrm{~b}$ & $0.252 a, b$ & $0.145 a, b$ & $0.063 \mathrm{~d}, \mathrm{e}$ & $4.41 b, c$ & $1.030 \mathrm{~b}, \mathrm{c}$ & $0.983 \mathrm{~b}, \mathrm{c}$ & $41.30 \mathrm{C}$ \\
\hline $45: 15$ & $4949.62 \mathrm{e}$ & $1234.01 \mathrm{~d}, \mathrm{e}$ & $0.250 \mathrm{a}-\mathrm{c}$ & $0.152 \mathrm{a}, \mathrm{b}$ & $0.096 \mathrm{~b}, \mathrm{c}$ & $4.06 \mathrm{c}, \mathrm{d}$ & $1.034 a, b$ & $0.984 a, b$ & $45.90 \mathrm{~b}$ \\
\hline $60: 0$ & $3918.37 f$ & $886.20 f$ & $0.235 a-d$ & $0.153 a$ & $0.102 \mathrm{a}-\mathrm{c}$ & $4.01 \mathrm{~d}$ & $1.033 \mathrm{a}, \mathrm{b}$ & $0.987 \mathrm{a}$ & $62.45 \mathrm{a}$ \\
\hline $15: 60$ & $8680.62 b$ & $1653.00 \mathrm{c}$ & $0.195 \mathrm{e}$ & $0.115 c$ & $0.115 a, b$ & $5.22 \mathrm{a}$ & $1.023 \mathrm{~d}$ & $0.982 b, c$ & $35.95 \mathrm{~d}$ \\
\hline $30: 45$ & $4783.37 e$ & 1037.55 e,f & $0.222 \mathrm{c}-\mathrm{e}$ & $0.145 a, b$ & $0.101 \mathrm{a}-\mathrm{c}$ & $4.10 \mathrm{c}, \mathrm{d}$ & $1.032 \mathrm{a}, \mathrm{b}$ & $0.986 \mathrm{a}$ & $40.60 \mathrm{c}$ \\
\hline $45: 30$ & $6043.00 d$ & $1385.19 \mathrm{~d}$ & $0.231 b-d$ & $0.146 \mathrm{a}, \mathrm{b}$ & $0.084 \mathrm{c}, \mathrm{d}$ & $4.18 \mathrm{c}, \mathrm{d}$ & $1.031 b$ & $0.982 b, c$ & $45.15 b$ \\
\hline $60: 15$ & $4760.25 e$ & $1099.76 \mathrm{e}, \mathrm{f}$ & $0.237 a-c$ & $0.144 a, b$ & $0.096 \mathrm{~b}, \mathrm{c}$ & $4.17 \mathrm{c}, \mathrm{d}$ & $1.031 b$ & $0.985 \mathrm{a}, \mathrm{b}$ & $62.45 \mathrm{a}$ \\
\hline $60: 60$ & $4121.87 f$ & $1001.19 f$ & $0.260 \mathrm{a}$ & $0.152 a, b$ & $0.118 a$ & $3.97 \mathrm{~d}$ & $1.036 \mathrm{a}$ & $0.977 d$ & $63.77 \mathrm{a}$ \\
\hline$F$ values & 173.58 & 52.63 & 6.54 & 13.31 & 14.57 & 13.13 & 8.55 & 11.40 & 1395.66 \\
\hline$p$ Values & $<0.001$ & $<0.001$ & $<0.001$ & $<0.001$ & $<0.001$ & $<0.001$ & $<0.001$ & $<0.001$ & $<0.001$ \\
\hline \multicolumn{10}{|l|}{$\begin{array}{l}\text { B: A freeze/ } \\
\text { thaw cycle }\end{array}$} \\
\hline FM potatoes & $4384.45 b$ & $1107.91 \mathrm{~b}$ & $0.256 a$ & $0.158 a$ & $0.108 a$ & $3.85 b$ & $1.036 \mathrm{a}$ & $0.989 a$ & $43.62 \mathrm{a}$ \\
\hline F/TM potatoes & $8072.82 \mathrm{a}$ & $1740.59 a$ & $0.212 b$ & $0.127 b$ & $0.071 b$ & $4.72 \mathrm{a}$ & $1.025 b$ & $0.978 b$ & $44.03 a$ \\
\hline$F$ values & 1665.61 & 308.00 & 90.49 & 261.67 & 129.66 & 209.77 & 207.99 & 464.13 & 3.17 \\
\hline $\begin{array}{l}p \text { Values } \\
\text { Interaction } A B\end{array}$ & $<0.001$ & $<0.001$ & $<0.001$ & $<0.001$ & $<0.001$ & $<0.001$ & $<0.001$ & $<0.001$ & 0.089 \\
\hline$F$ values & 37.80 & 16.60 & 1.64 & 3.78 & 9.86 & 6.65 & 4.57 & 12.84 & 5.13 \\
\hline$p$ Values & $<0.001$ & $<0.001$ & 0.114 & 0.001 & $<0.001$ & $<0.001$ & $<0.001$ & $<0.001$ & $<0.001$ \\
\hline
\end{tabular}

SPI: soy protein isolate; INL: inulin.

Means for the same factor with common alphabets did not differ significantly $(p \geq 0.01)$.

$G^{\prime}$, storage modulus; $G^{\prime \prime}$, loss modulus; tan $\delta$, loss tangent; $G^{*}$, complex modulus; dynamic moduli were taken at frequency $(\omega)$ of $1 \mathrm{rad} \mathrm{s}^{-1}, n^{\prime}$ and $n^{\prime \prime}$, slopes of linear regressions of $\ln \left(G^{\prime}\right)$ and $\ln \left(G^{\prime \prime}\right)$ vs. $\ln (\omega)$. 
opaque gels (see microstructure examination subsection) and hence their presence had a greater impact on the elastic rather than on the viscous response. Also, in INL-waxy maize starch systems, pure INL samples with a $40 \%$ total polymer concentration presented the typical characteristics of a highly crystalline polymer in which the difference between $G^{\prime}$ and $G^{\prime \prime}$ became larger and the moduli became more frequency-independent as INL concentration increased (Zimeri and Kokini, 2003a). The lower contribution of $G^{\prime \prime}$ to the viscoelasticity of the F/TM potatoes is probably the result of water vapor lost when the product is frozen.

However, by considering the $G^{\prime}$ values, both supplementary additions of INL and SPI at $15 \mathrm{~g} \mathrm{~kg}^{-1}$ exhibited a significant $(p<0.01)$ strengthening effect on the samples with added SPI and INL alone, respectively. Addition of $15 \mathrm{~g} \mathrm{~kg}^{-1}$ SPI strengthened the network of amylose/amylopectin with INL added alone, which was demonstrated by the increase in gel storage modulus up to $8.84 \%$ (15:60 vs. $0: 60$, Table 1$)$. In turn, presence of $15 \mathrm{~g} \mathrm{~kg}^{-1}$ INL in the system enhanced strongly the elasticity of the samples with added SPI alone by increasing the $G^{\prime}$ value up to a $21.48 \%(60: 0$ vs. $60: 15)$. Thereby, INL presence must have a synergistic effect on SPI gelation. Analogously, the addition of $5 \%(w / v)$ INL enhanced the gelation of SPI and the $7 \mathrm{~S} / 11 \mathrm{~S}$ mixture, which was evidenced by increases in gel $G^{\prime}$ up to 13.6 and $10.1 \%$, respectively (Tseng et al., 2009). According to the latter authors, the exclude volume effect is likely the major force driving soy globulins into a more stable state in the presence of this neutral carbohydrate.

Anyway, the ANOVA also showed that the binary interaction between the factors studied had a significant effect on rheological properties and characteristics (Table 1), except for $\tan \delta$. Shown in Figure 3 are the interactions for dynamic functions, $G^{\prime}$ and $G^{\prime \prime}$. A high correlation $(r=0.94)$ was found between elasticity and viscosity of the samples. In all cases, $G^{\prime}$ was significantly lower in the FM than in the F/TM potatoes (Figure $3(\mathrm{~A})$ ). $G^{\prime \prime}$ was also significantly lower in the FM samples than in their F/TM counterparts, except for samples with $0: 0$ and $0: 60$ ratios (Figure $3(\mathrm{~B})$ ). This could be explained as follows: (a) as expected the $\mathrm{F} / \mathrm{TM}$ potatoes had a lower $\mathrm{a}_{\mathrm{w}}$ value (see other physical and chemical characteristics subsection) and (b) XG does not prevent ice recrystallization or amylopectin retrogradation (Arocas et al., 2009), consequently both phenomena could be responsible for the overall structure reinforcement observed in the F/TM samples. Analogously, Cancela et al. (2007) observed that sample viscosity increased when commercial cream was exposed to freeze-thaw treatment with respect to the not treated sample.

Note that the increase in the $G^{\prime}$ values of F/TM samples compared to their FM counterparts were almost non-significant in samples with $0: 0$ and $0: 60$ ratios (Figure $3(\mathrm{~A})$ ) that is to say where SPI was absent. This suggests that SPI freezing and thawing increases the differences in the rheological behavior of

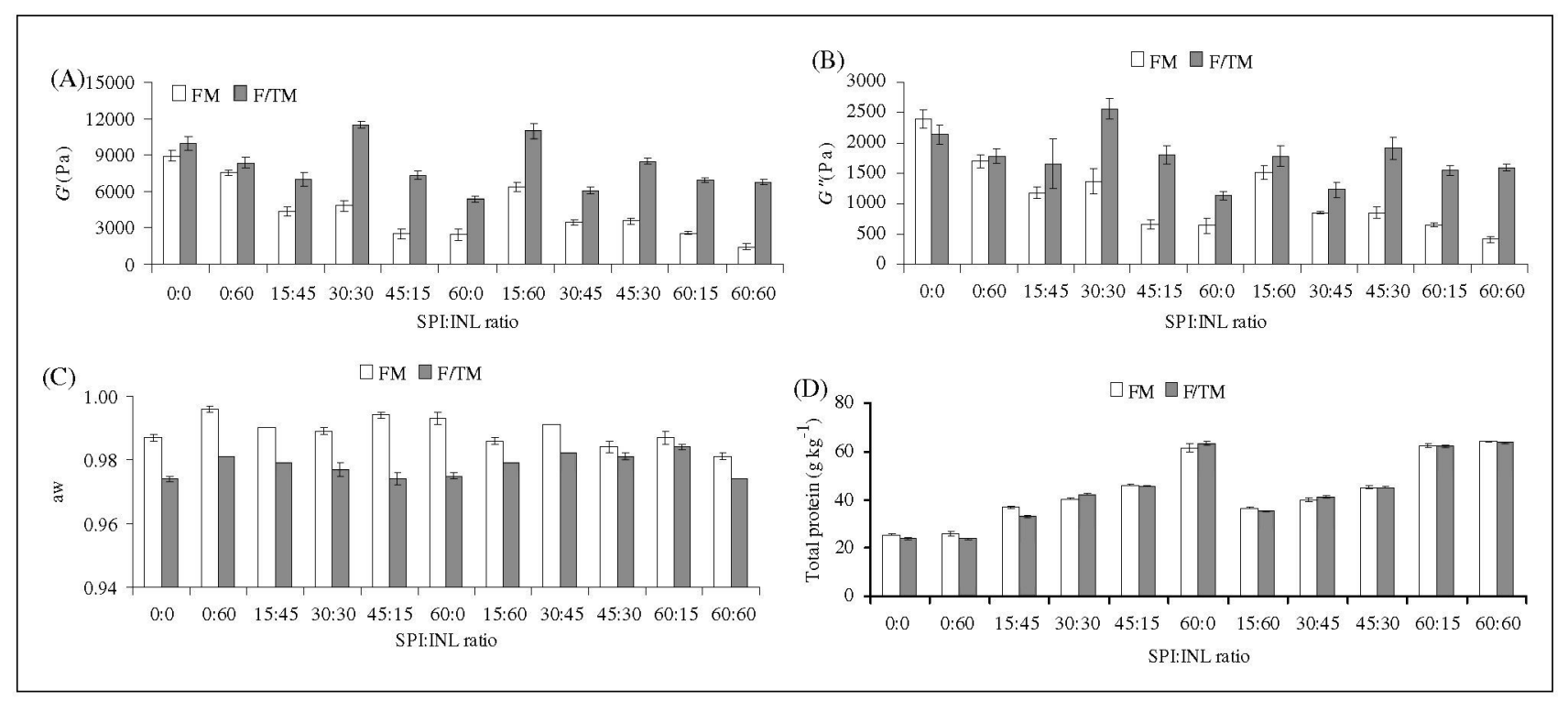

Figure 3. Rheological properties and physical and chemical characteristics of fresh mashed (FM) and frozen/thawed mashed potatoes (F/TM) with different added SPI:INL ratios. (A) Storage modulus at $1 \mathrm{rad} \mathrm{s}^{-1}$, (B) Loss modulus at $1 \mathrm{rad} \mathrm{s}^{-1}$, (C) Water activity and (D) Total protein content. INL: inulin; SPI: soy protein isolate. 
the F/TM potatoes by reinforcing more the gel structure of the products as compared to their FM counterparts. Consequently, SPI presence reduced the freeze/ thaw stability conferred by the XG and $\kappa$-C mixture. The amount of water covering the surface of a protein in a fully hydrated state is around $0.3 \mathrm{~g} \mathrm{~g}^{-1}$ protein while the water content of a dried protein product is usually less than $0.1 \mathrm{~g} \mathrm{~g}^{-1}$ (Li et al., 2007). Thus, the freezing process probably removed part of the hydration layer, which in turn disrupted the protein structure and caused superior aggregation, as well as structural changes in some functional properties of soluble and insoluble fractions. Protein aggregation and gelation are closely related and the aggregation pattern influences the rheological characteristics of the resulting gel (Tseng et al., 2009).

All FM samples had significantly lower $G^{\prime}$ and $G^{\prime \prime}$ values than the FM 0:0 control (Figure 3(A) and (B)). The lowest $G^{\prime}$ and $G^{\prime \prime}$ values with respect to the FM $0: 0$ control were recorded at a ratio of $60: 60$, indicating that in the systems with higher total SPI/INL content, both ingredients behaved as softer fillers. At a fixed total concentration of $60 \mathrm{~g} \mathrm{~kg}^{-1}$, the $G^{\prime}$ and $G^{\prime \prime}$ values were higher at a ratio of $0: 60$ and lower at ratios of $45: 15$ and $60: 0$, visibly indicating that the addition of INL alone caused rather less softening than adding SPI alone. Also, with a fixed concentration of $75 \mathrm{~g} \mathrm{~kg}^{-1}$, the $G^{\prime}$ and $G^{\prime \prime}$ values were higher at a ratio of $15: 60$ and lower at a ratio of $60: 15$. Ronkart et al. (2010) reported that both INL concentration and the microfluidization process increased $G^{\prime}$ and $G^{\prime \prime}$ values considerably. Such increases were due to a decrease in particle size and the formation of a network composed of agglomerates interacting with the solution. In low-fat and whole milk set yoghurts enriched with INL, the INL increase was almost linear for the increase in yield stress values (Guggisberg et al., 2009).

However, in FM samples with a fixed SPI concentration, the $G^{\prime}$ and $G^{\prime \prime}$ values increased as the INL content increased in the ratios $15: 45$ vs. $15: 60$ and $45: 15$ vs. $45: 30$. It was apparent that INL modulated the aggregation and gelation of SPI, and the effect depended on protein concentration, SPI : INL ratio and possibly solvent properties (e.g., $\mathrm{a}_{\mathrm{w}}$ ). In contrast, at a fixed INL concentration, most $G^{\prime}$ and $G^{\prime \prime}$ values decreased with increasing SPI content $(0: 60$ vs. $15: 60$, $15: 45$ vs. $30: 45$ and $30: 30$ vs. $45: 30$ ). In this study, SPI was heated at $90^{\circ} \mathrm{C}$ for $5 \mathrm{~min}$. This heating dissociates the compact glycinin and $\beta$-conglycinin oligomers into monomers, and, in doing so, the hydrophobic groups were exposed (Sorgentini et al., 1995; Tseng et al., 2009), to facilitate their interaction with INL and the rest of ingredients. On the other hand, thermo-

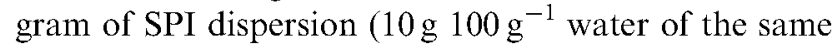
sample) showed the thermal denaturation of SPI (glycinin, $11 \mathrm{~S}$ ) at $90^{\circ} \mathrm{C}$ (Ahmed et al., 2008). Possibly, the brief heat treatment of SPI produced total $7 \mathrm{~S}$ denaturation, though more likely only a partial denaturation of $11 \mathrm{~S}$ protein. This facilitated the obtention of soluble and insoluble fractions progressively enriched in native $11 \mathrm{~S}$ protein by increasing SPI concentration (Sorgentini et al., 1995). In turn, van Vliet (1988) suggested that the rheological properties of deformable particles would be as if the particles were made of water. The existence of an aqueous boundary layer may be one viable explanation for the rheological data in the present study. As stress was applied to the system, small amounts of water may be released from the SPI aggregate particles, thus forming an aqueous boundary layer around them, which decreased the final gel rigidity ( $G^{\prime}$ value).

F/TM samples with added $30: 30$ ratio had significantly higher $G^{\prime}$ and $G^{\prime \prime}$ values with respect to the frozen/thawed 0:0 control (Figure 3(A) and (B)), again suggesting a possible synergistic effect between both ingredients. F/TM samples with an added 15:60 ratio also had significantly higher elasticity than both $0: 0$ controls. The lowest $G^{\prime}$ and $G^{\prime \prime}$ values were recorded in samples enriched with only SPI. In F/TM potatoes with a fixed concentration of $60 \mathrm{~g} \mathrm{~kg}^{-1}$, samples with added blend ratios of $15: 45,45: 15$ and $60: 0$ had significantly lower elasticity than samples enriched only with INL, while in processed samples with higher total concentration $\left(75 \mathrm{~g} \mathrm{~kg}^{-1}\right)$, the $G^{\prime}$ values were higher at a ratio of 15:60 and lower at 30:45 (Figure 3(A)). There was no linear decrease in $G^{\prime \prime}$ values with increasing SPI and decreasing INL contents. Neither were there any significant differences in the viscosity of F/TM samples with added $60: 15$ and $60: 60$ ratios. This result suggests that in frozen/thawed samples, the effect of the SPI : INL blend ratio on elasticity and viscosity was partially masked by other factors.

Certainly, other components of the mashed potatoes, such as milk proteins, can also play a part in the development of viscosity or in the structure of the systems under study. There seems to be no doubt that the addition of milk protein ingredients affects the swelling of starch granules and the leaching of amylose and amylopectin molecules from the starch granules (Arocas et al., 2009). In the present case, since the milk proteins are at a natural $\mathrm{pH}$ value (above their isoelectric point) the possibility of interactions developing is minimized, and since they are at the same concentration in all the systems studied, their effect will be of similar size in comparisons.

\section{Other physical and chemical characteristics}

Shown in Table 1 are also the effects produced by both the SPI : INL blend ratio and a freeze/thaw cycle on the 
values of $\mathrm{a}_{\mathrm{w}}$ and total protein. SPI : INL ratio and interaction had a significant effect on the two characteristics, while only $a_{w}$ values were also affected by the freeze/ thaw cycle. The lowest $\mathrm{a}_{\mathrm{w}}$ value corresponded to mashed potatoes with an added blend ratio of $60: 60$, although there was a non-significant difference between the $a_{w}$ values of these samples and those of the $0: 0$ controls. Consequently, in mashed potatoes with an added 60:60 ratio less free water was available, probably because both INL and SPI gels needed water in their structures. One might argue that a reduced $\mathrm{a}_{\mathrm{w}}$ in the presence of concentrated carbohydrates could also make the water-protein interactions less effective (Tseng et al., 2008), although there was no significant difference $(p \geq 0.01)$ between SPI-only sample (mean $\left.\mathrm{a}_{\mathrm{w}}=0.930\right)$ and the samples containing INL and oligofructose (mean $\mathrm{a}_{\mathrm{w}}=0.927$ to 0.931 ). On the other hand, water availability increases when proteins denature due to shrinkage and expulsion of water that is held by capillary forces (Ahmed et al., 2008). A freeze/thaw cycle reduced the $\mathrm{a}_{\mathrm{w}}$ of the mashed potatoes; this fact is not only related to moisture loss due to migratory recrystallization but to evaporative loss during microwave thawing as well. Figure 3(C) shows that FM samples with added blend ratios of $0: 60,15: 45,30: 30$, $45: 15,60: 0$ and $30: 45$ had significantly higher $a_{w}$ values than the control, indicating that either SPI or INL are hygroscopic ingredients. At a fixed concentration of $60 \mathrm{~g} \mathrm{~kg}^{-1}, \mathrm{FM}$ samples enriched with either SPI or INL alone or with an added 45:15 ratio had similar $\mathrm{a}_{\mathrm{w}}$ values, suggesting that both ingredients are capable of attracting and holding water molecules. In F/TM potatoes, there was a non-significant difference between the $a_{w}$ values of samples with added $0: 0,45: 15,60: 0$ and $60: 60$ ratios, which was lower than that for the rest of the samples.

As expected, total protein content of the samples increased linearly with increasing SPI content and was not affected by processing (Table 1, Figure 3(D)). However, it is known that SPI (whether prepared commercially or in a laboratory) consists of varying percentages of soluble and insoluble proteins, which are functions of temperature and isolate concentration (Sorgentini et al., 1995). The insoluble fraction percentage increases with the concentration, as a consequence of the marked increase in protein-protein interaction (gel formation). Probably, at the ratios with higher SPI concentrations, the insoluble SPI fraction increased, facilitating the loss of retained water from these samples.

\section{Microstructure examination}

Shown in Figures 4 and 5 are the mashed potato microstructures corresponding to samples made with selected
SPI:INL blends. Micrographs clearly indicated the structural domains at each combination used. Both FM and F/TM 0:0 controls (Figure 4(A) and (B)) consisted mainly of a continuous phase (amylose/amylopectin matrix) due to the disruption and complete solubilization of the potato starch granules. In the F/TM 0:0 control (Figure 4(B)), the tissue presents a more dehydrated appearance, since part of the intracellular water was drawn out osmotically when the product was thawed because of freezing-induced concentration of the cell mass. In turn, samples with added INL alone (Figure 4(C) and (D)) and with added 15:45 ratio (Figure 4(E,F)) had an INL-rich phase with small INL crystallites forming a continuous network, which gave a completely different appearance to that of the $0: 0$ controls. Indeed, at a ratio of $15: 45$, INL masked the SPI presence possibly due to that at $15 \mathrm{~g} \mathrm{~kg}^{-1} \mathrm{SPI}$ formed few aggregates. Conversely, it is clear that in these ratios INL crystallites were dispersed throughout a continuous matrix, forming a gel with characteristics of a one-phase system. Analogously, in INL-waxy maize starch systems, as soon as INL concentration reached $c^{*}$ (limiting concentration between a dilute and a semi-dilute solution), it formed a continuous, crystalline phase (Zimeri et al., 2003a).

Figure $4(\mathrm{C}-\mathrm{F})$ confirms the presence of INL gel structure reinforcing the hypothesis of an INL gelation mechanism previously proposed by Kim et al. (2001) and Ronkart et al. (2010). The long-chain INL structure resembles that of a network of fat crystals in oil, since this type of INL forms small microcrystal aggregates that occlude a considerable amount of water (Bot et al., 2004; Guggisberg et al., 2009). In any case, there are some slight differences between samples with added $0: 60$ and $15: 45$ ratios. When INL was added alone (Figure 4(C) and (D)) the clusters of small INL crystals were more strongly fused together. Higher INL concentrations led to more particle interactions and to a more highly aggregated microstructure, as reflected by higher final gel rigidity ( $G^{\prime}$ value) obtained for these samples, when compared with that of samples with an added $15: 45$ ratio (Figure $3(\mathrm{~A})$ and $(\mathrm{B})$ ). The small size of the crystallites was caused by a concentrated INL phase, which facilitated nucleation (Zimeri and Kokini, 2003b). Even in the F/TM samples with added $0: 60$ and 15:45 ratios (Figure 4(D) and (F)), loss of water due to freezing and thawing processes provoked the formation of closer packed INL crystallites in the INL-rich phase as compared to FM counterparts (Figure $4(C)$ and $(E)$ ).

In the case of FM and F/TM samples with added blend ratios of $30: 30$ (Figure $4(\mathrm{G})$ and $(\mathrm{H})$ ), the INL did not form a continuous phase, since its lower concentration reduced the density of these particles in the product. Spherical and obloid-shaped INL crystallites 

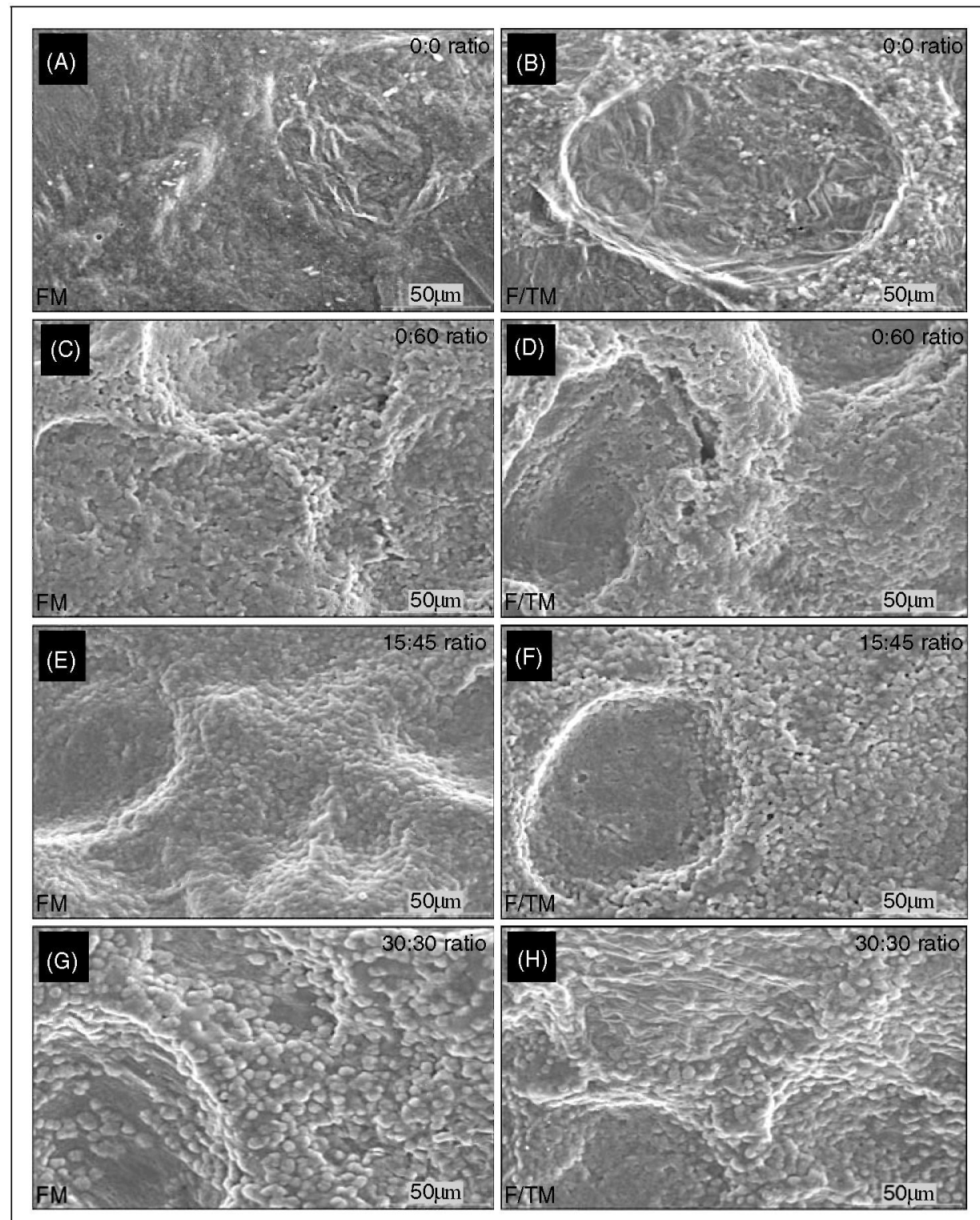

Figure 4. Micrographs of fresh mashed (FM) and frozen/thawed mashed potatoes (F/TM) with different added SPI:INL ratios. (A) FM with 0:0 ratio, (B) F/TM with 0:0 ratio, (C) FM with added 0:60 ratio, (D) F/TM with added 0:60 ratio, (E) FM with added 15:45 ratio, (F) F/TM with added 15:45 ratio, (G) FM with added 30:30 ratio and (H) F/TM with added $30: 30$ ratio. INL: inulin; SPI: soy protein isolate.

can be distinguished throughout the FM samples (Figure $4(\mathrm{G})$ ), although with fewer interconnections between them, and which were again more visibly fused together in the F/TM samples (Figure 4(H)). Micrographs of samples with an added $30: 30$ ratio also revealed the presence of some fine SPI fibers or strands. Under an enough SPI concentration condition, addition of INL probably caused more $\mathrm{a}_{\mathrm{w}}$ reduction (Figure $3(\mathrm{C})$ ), exerted stronger hydrogen bonding with water and/or had greater physical interactions (e.g., entanglement) with SPI molecules (Tseng et al., 2009). Such reactions, combined with the exclude volume effect, would lead to an enhancement proteinprotein interactions as manifested by the increase in elasticity and viscosity significantly indicating reduced freeze/thaw stability.

Figure 5 shows micrographs of FM and F/TM potatoes with added blend ratios of $45: 15,60: 0$, 15:60 and 60:60. Only some INL crystallites can be distinguished at a 45:15 ratio, mainly in the $F / T M$ sample (Figure 5(A) and (B)) due to that INL crystallization process depends on both the size of the INL chains and the initial INL concentration (Bot et al., 2004). In contrast, at both $45: 15$ and $60: 0$ ratios, SPI 


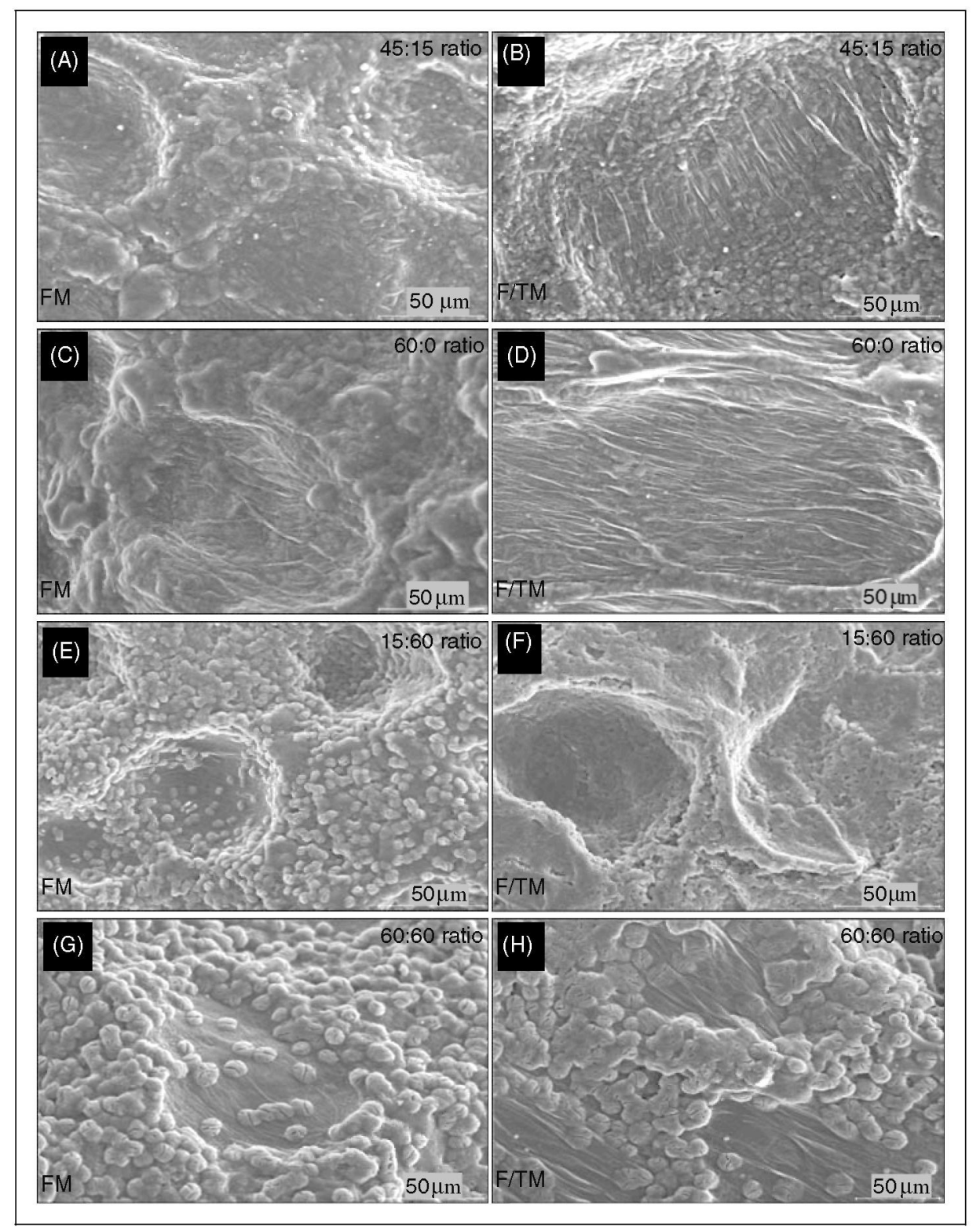

Figure 5. Micrographs of fresh mashed (FM) and frozen/thawed mashed potatoes (F/TM) with different added SPI:INL ratios. (A) FM with added 45:15 ratio, (B) F/TM with added 45:15 ratio, (C) FM with added 60:0 ratio, (D) F/TM with added $60: 0$ ratio, (E) FM with added 15:60 ratio, (F) F/TM with added 15:60 ratio, (G) FM with added 60:60 ratio and (H) F/TM with added 60:60 ratio. INL: inulin; SPI: soy protein isolate.

formed fine-stranded, orderly gel networks, which are again especially noticeable in the F/TM samples (Figure 5(B) and (D)). The freeze/thaw cycle increased SPI gel coarsening. $7 \mathrm{~S}$ and $11 \mathrm{~S}$ globulins were isoelectrically precipitated at $\mathrm{pH} 4.8$ and 6.4 , respectively (Nagano et al., 1992). Therefore, at pH 5.9, the majority of $11 \mathrm{~S}$ globulins would be positively charged, while most $7 \mathrm{~S}$ globulins would carry a negative charge. The attractive electrostatic interaction would promote SPI aggregation, producing large strands. Some clusters of aggregates can also be visualized in the FM samples (Figure 5(A) and (C)).
Generally, for globular proteins two different types of gel network can be distinguished: fine-stranded and coarse networks (Lakemond et al., 2003). In finestranded networks, the proteins are attached to each other like a string of beads. Stading and Hermansson (1990) found that $10 \%-12 \%$ solutions of $\beta$-lactoglobulin preheated to $90-95^{\circ} \mathrm{C}$ formed fine-stranded gels with flexible or rigid strands at low and high $\mathrm{pH}$. Conversely, Tseng et al. (2008) showed that SPI gels exhibited a particulate porous network structure. In turn, differences between FM and F/TM potatoes with added 45:15 and 60:0 ratios must be the result 
of many more proteins becoming insoluble because of the freeze/thaw cycle which favor protein intermolecular association. Enhanced hydrophobic interactions and intermolecular disulphide linkages (Hashizume et al., 1971) are probably responsible for the more orderly and denser SPI network of F/TM with an added 60:0 ratio (Figure 5(D)).

The appearance of FM with an added 15:60 ratio (Figure 5(E)) was quite similar to that of fresh samples with an added ratio of $30: 30$ (Figure $4(G)$ ), with a discontinuous INL network although without appreciable strand-like structures. In contrast, in $\mathrm{F} / \mathrm{TM}$ with an added 15:60 ratio (Figure 5(F)), a higher INL content again facilitated agglomeration into a densely packed structure with monophasic behavior. For this SPI : INL ratio, the $G^{\prime}$ magnitude increased in $\mathrm{F} /$ TM samples, indicating a stronger gel behavior and reduced freeze/thaw stability (Figure 3(A)). Finally, the presence of both ingredients at the same highest concentration (Figure $5(\mathrm{G})$ and $(\mathbf{H})$ ) ratio led to more obvious biphasic behavior with larger INL crystallites than those found for lower total concentration. Guggisberg et al. (2009) stated that long-chain INL at high concentrations occlude large amounts of water. The larger the crystals were, the more water they were able to hold. Possibly, during the final phase of the manufacturing process, both INL and SPI compete for the available water, which is in part entrapped by the INL. Water trapped by the SPI gel network can be more easily removed, and the more fluid-like behavior observed in these samples may be attributed to either a possible release of water from the SPI gel in the discontinuous phase or to the bigger INL crystal size. After the freeze/thaw cycle, samples with an added 60:60 ratio showed either larger crystalline aggregates or the existence of SPI gel made up of significantly thicker strands (Figure 5(H)) and probably with more insoluble protein present in the threads. On the whole, SPI and INL are self-associating and there was no evidence of interaction between them; these are segregative phase separated blends due to thermodynamic incompatibility (Tolstoguzov, 1985).

\section{CONCLUSIONS}

HPAEC-PAD analyses have showed that the freeze/ thaw cycle did not influence the DP of the INL. Neither, INL chemical structure was affected by SPI enrichment. Consequently, F/TM potatoes with added blend ratios of SPI : INL retain the INL prebiotic effect. Nevertheless, SPI significantly increased the differences in the rheological behavior between FM samples and their F/TM counterparts, therefore reducing the freeze/ thaw stability conferred by XG and $\kappa-C$. The way the freeze/thaw cycle affects the soluble and insoluble SPI fractions needs to be studied. The presence of INL was found to enhance the texture of mashed potatoes with added SPI alone by increasing the gel elasticity $\left(G^{\prime}\right.$ value). An increase in the daily intake of soluble fiber and/or soy protein can be achieved, depending on one's requirements, by adding $0: 60,15: 45,45: 15,45: 30$, $60: 15$ and $60: 60$ blend ratios to the products destined to be frozen and thawed, while leading to a less structured system with reduced increase in viscoelastic function values after the freeze/thaw cycle. Results have shown that in the systems, SPI-water interactions are weaker than those between INL and water. INL gel was not negatively influenced by adding SPI, probably due to that there was no interaction between both gels as evidenced by SEM. An upcoming work will investigate the perceived texture of mashed potatoes supplemented with SPI/INL blends, to see if this sensory property can be explained by rheological and structural characteristics.

\section{FUNDING}

II.

\section{ACKNOWLEDGEMENTS}

The authors wish to thank the Spanish Ministry of Economy and Competitiveness for financial support (AGL2007-62851 and AGL2011-28569), P Adeva, I Amurrio and A García of the Electron Miscroscopy Laboratory (CENIM-CSIC) and E. de Vega for her assistance with HPAEC-PAC analysis.

\section{REFERENCES}

Ahmed J, Ramaswamy HS and Raghavan GSV. (2008). Dielectric properties of soybean protein isolate dispersions as a function of concentration, temperature and $\mathrm{pH}$. LWT-Food science and Technology 41(1): 71-81.

Alvarez MD, Fernández C and Canet W. (2009). Enhancement of freezing stability in mashed potatoes by the incorporation of kappa-carrageenan and xanthan gum blends. Journal of the Science of Food and Agriculture 89(12): 2115-2127.

Alvarez MD, Fernández C, Solas MT and Canet W. (2011). Viscoelasticity and microstructure of inulin-enriched mashed potatoes: influence of freezing and cryoprotectants. Journal of Food Engineering 102(1): 66-76.

Arocas A, Sanz T and Fiszman SM. (2009). Improving effect of xanthan and locust bean gums on the freeze-thaw stability of white sauces made with different native starches. Food Hydrocolloids 23(8): 2478-2484.

Bot A, Erle U, Vreeker R and Agterof W. (2004). Influence of crystallisation conditions on the large deformation rheology of inulin gels. Food Hydrocolloids 18(4): 547-556.

Canet W. (1989). Quality and stability of frozen vegetables. In: Thorne S (ed.) Developments in Food Preservation. London: Elsevier, pp. 1-50.

Cancela A, Maceiras R, Delgado-Bastidas N and Alvarez E. (2007). Rheological properties of cooking creams: effect of 
freeze-thaw treatment. International Journal of Food Engineering 3(3) Article 6.

Chiavaro E, Vittadini E and Corradini C. (2007). Physicochemical characterization and stability of inulin gels. European Food Research \& Technology 225(1): 85-94.

Coussement PAA. (1999). Inulin and oligofructose: safe intakes and legal status. Journal of Nutrition 129(7): 1412S-1417S.

Federal Register. (1998). Food labeling: health claim soy protein and coronary heart disease. Federal Register 63: 62977-63015.

Glibowski P and Wasko A. (2008). Effect of thermochemical treatment on the structure of inulin and its gelling properties. International Journal of Food Science and Technology 43(11): 2075-2082.

González-Tomás L, Coll-Marqués J and Costell E. (2008). Viscoelasticity of inulin-starch-based dairy systems. Influence of inulin average chain length. Food Hydrocolloids 22(7): 1372-1380.

Guggisberg D, Cuthbert-Steven J, Piccinali P, Bütikofer U and Eberhard P. (2009). Rheological, microstructural and sensory characterization of low-fat and whole milk set yogurt as influenced by inulin addition. International Dairy Journal 19(2): 107-115.

Hagenimana A, Ding X and Gu W-Y. (2007). Steady state flow behaviours of extruded blend of rice flour and soy protein concentrate. Food Chemistry 101(1): 241-247.

Hashizume K, Kakiuchi K, Koyama E and Watanabe T. (1971). Denaturation of soy protein by freezing. Agricultural \& Biological Chemistry 35: 449-459.

Jampen S, Britt IJ, Yada S and Tung MA. (2001). Rheological properties of gellan gels containing filler particles. Journal of Food Science 66(2): 289-293.

Kim Y, Faqih MN and Wang SS. (2001). Factors affecting gel formation of inulin. Carbohydrate Polymers 46(2): 135-145.

Lakemond CMM, de Jongh HHJ, Paques M, van Vliet T, Gruppen H and Voragen GJ. (2003). Gelation of soy glycinin; influence of $\mathrm{pH}$ and ionic strength on network structure in relation to protein conformation. Food Hydrocolloids 17(3): 365-377.

Leroy G, Grongnet JF, Mabeau S, Le Corre D and Baty-Julien C. (2010). Changes in inulin and soluble sugar concentration in artichokes (Cynara scolymus L.) during storage. Journal of the Science of Food and Agriculture 90(7): 1203-1209.

Li X, Li Y, Hua Y, Qiu A, Yang C and Cui S. (2007). Effect of concentration, ionic strength and freeze-drying on the heat-induced aggregation of soy proteins. Food Chemistry 104(4): 1410-1417.

Moore JC, De Vries JW, Lipp M, Griffiths JC and Abernethy DR. (2010). Total protein methods and their potential utility to reduce the risks of food protein adulteration. Comprehensive Reviews in Food Science and Food Safety 9: $330-357$

Nagano T, Hirotsuka M, Mori H, Kohyama K and Nishinari K. (1992). Dynamic viscoelastic study on the gelation of $7 \mathrm{~S}$ globulin from soybeans. Journal of Agricultural and Food Chemistry 40(6): 941-944.

Roberfroid MB. (2007). Inulin-type fructans: functional food ingredients. Journal of Nutrition 137: 2493S-2502S.

Ronkart SN, Paquot M, Deroanne C, Fougnies C, Besbes S and Blecker CS. (2010). Development of gelling properties of inulin by microfluidization. Food Hydrocolloids 24(4): $318-324$.

Sorgentini DA, Wagner JR and Anon MC. (1995). Effects of thermal-treatment of soy protein isolate on the characteristics and structure-function relationship of soluble and insoluble fractions. Journal of Agricultural and Food Chemistry 43(9): 2471-2479.

Stading M and Hermansson A-M. (1990). Viscoelastic behaviour of $\beta$-lactoglobulin gel structures. Food Hydrocolloids 4(2): $121-135$.

Tolstoguzov VB. (1985). Functional properties of proteinpolysaccharide mixtures. In: Mitchell JR and Ledward DA (eds) Functional Properties of Food Macromolecules. London: Elsevier Science, pp. 171-202.

Tseng Y-C, Xiong YL and Boatright WL. (2008). Effects of inulin/oligofructose on the thermal stability and acidinduced gelation of soy proteins. Journal of Food Science 73(2): E44-E50.

Tseng Y-C, Xiong YL and Yang F. (2009). Influence of inulin/oligofructose on the acid-induced cold aggregation and gelation of preheated soy proteins. Journal of the Science of Food and Agriculture 89: 2650-2658.

Tunick MH. (2011). Small-strain dynamic rheology of food protein networks. Journal of Agricultural and Food Chemistry 59: 1481-1486.

van Vliet T. (1988). Rheological properties of filled gels: Influence of filler matrix interaction. Colloid and Polymer Science 266: 518-524.

Wada T, Sugatani JN, Terada E, Ohguchi M and Miwa M. (2005). Physicochemical characterization and biological effects of inulin enzymatically synthesized from sucrose. Journal of Agricultural and Food Chemistry 53: 1246-1253.

Zimeri JE and Kokini JL. (2003a). Rheological properties of inulin-waxy maize starch systems. Carbohydrate Polymers 52: $67-85$.

Zimeri JE and Kokini JL. (2003b). Morphological characterization of the phase behaviour of inulin-waxy maize starch systems in high moisture environments. Carbohydrate Polymers 52: 225-236. 